\title{
Kantian Normal Idea vs Santayana's 'Psychology' of Defining Characters as Aesthetic Forms
}

\begin{abstract}
The objective of the presented article consists in the juxtaposition of two depictions of mechanisms of imagination which we use to create averaged images of all sensual experiences. The first of them is Kantian normal idea conducive to the construction of adherent beauty, whereas the second - Santayana's concept of formation of a generic idea, aesthetic type or an ideal. It is my conviction that both these proposals are convergent, as they refer to the same method of functioning of the imagination, however they differ in certain details, as they are inscribed in nearly entirely opposite aesthetic concepts. However, Santayana's theory of character creation goes further than Kant's concept, as it exceeds the averaged image of the normal idea, and, while not being equivalent to Kantian aesthetic idea constituting a certain product of genius, it heads towards the idealisation of representations available to all people. The purpose behind Santayana's concept proves to be more practical as compared to the solution proposed by Kant. In this depiction, we should recognise a universal mechanism of the imagination in the formation of characters as aesthetic forms, enabling a person to define his/her place and gain knowledge on the human world of attitudes, customs and ordinary behaviours.
\end{abstract}

1 Department of British Philosophy, the Institute of Philosophy, Nicolaus Copernicus University in Toruń, Poland, kwawrzonkowski@umk.pl. 


\section{Keywords:}

Santayana, Kant, imagination, normal idea, adherent beauty, literary character

It is not my intention to argue that George Santayana (1863-1952) was in any way inspired by Immanuel Kant's aesthetics (1724-1804). Conversely, it appears that he was prejudiced to it to a certain extent, which might have been attributable to its dissimilar epistemological underpinnings on one hand, and the circumstances for the feasibility of pure judgements of taste, as presented by the philosopher from Konigsberg, to which the author of The Sense of Beauty ${ }^{2}$ was rather aloof ${ }^{3}$ on the other. This in turn affected his inadequate comprehension of the opinions expressed in the third Critique of the Power of Judgment, or even their distortion. Regardless of all the differences, one may indicate certain similarities between both concepts. One of them is the Kantian definition of the normal idea as an averaged image conditioned by the experience of an individual, which recognises the mechanism of how imagination functions to such a degree that it can be found in the works of other aestheticians, including Sanatayana (1896), who employs it to explicate the emergence of all generic ideas, aesthetic types or even ideals ${ }^{4}$. Kant frees the normal idea from its inherent universality, resulting in the variety of instances of adherent beauty in different empirical conditions, which partially accounts for the individual character of artistic creativity and the multitude of its embodiments. The manner in which the sheer normal idea emerges from imagination remains unaltered and occurs in the same manner in everyone. It should therefore come as no surprise that different thinkers who undertake to ponder over it discern and point to similar principles of its operation. This must have been the case with Kant

\footnotetext{
2 See Santayana (1896).
}

3 First and foremost this concerns the unbiasedness of the judgements of taste. The title of paragraph 8 is characteristic of his opinions in this respect: The differentia of aesthetic pleasure not its disinterestedness. For Santayana’s attitude towards Kant see A. Grzeliński, K. Wawrzonkowski (2014).

4 One should make a reservation however, that inasmuch in The Sense of Beauty Santayana (1896) uses these concepts quite comfortably, sometimes interchangeably, then in Reason in Art (1905) the ideal understood in such a way is virtually non-existent. The reason is that it acquires a different and much broader meaning and application, which cannot be reduced to a sheer generalization of certain sensual experiences, with which we deal here. It certainly stems from the fact that The Sense of Beauty was Santayana's first work in aesthetics which, as he later himself admitted, he knew very little about. See Santayana, 1986, p. 393. For information on the period in life when The Sense of Beauty was written and the work itself see McCormick, 1988, pp. 123-139. 
and Santayana. They both saw the same mechanism, but they each put it to a different use. For the former, the normal idea was „only the form that constitutes the indispensable condition of all beauty, (...) the correctness in the presentation of the species” (Kant, 2000, p. 119), whereas the latter turned the generic idea into a prism through which each man interprets their experiences, also aesthetic ones, enabling them to find their bearings in life.

\section{KANTIAN NORMAL IDEA; THE CONSTRUCTION AND ROLE IN SPECIFYING ADHERENT BEAUTY}

In the 16th paragraph of Critique of the Power of Judgment, Kant (2000) introduces the division of beauty into free beauty (pulchritudo vaga) and adherent beauty (pulchritudo adhaerens) ${ }^{5}$. The former is the subject of pure judgements of taste characterised by unbiasedness, universality and necessity, as well as relating to the purposefulness of form of the evaluated object, without communicating to oneself this purpose by the person who is expressing such judgements at the same time $^{6}$. This type of beauty does not presuppose the notion of what the object is supposed to be. On the other hand, adherent beauty assumes that such a notion and perfection will be the internal purpose of the object. Hence we do not make pure judgements of taste about it. Unless, as Kant (2000) permits, we make judgements about the object which has a defined internal purpose abstracting from this purpose or by being unaware of it $^{7}$. Then, however, it will lead to the divergence

5 This division and the consequences that follow from it were on numerous occasions subject of research by such philosophers as Guyer (1997, 2005 and 2008), Dickie (1996) or Wenzel (2005).

6 At this juncture it should be recalled that all four moments of the judgements of taste must be fulfilled for us to talk about pure judgements of taste, i.e. such that have not been tainted by a tinge of predilection, interest in the subject or that which interests us , the notion of perfection or the intended use of the object.

7 See an interesting remark by Kant: „A judgment of taste in regard to an object with a determinate internal end would thus be pure only if the person making the judgment either had no concept of this end or abstracted from it in his judgment. But in that case, although this person would have made a correct judgment of taste, in that he would have judged the object as a free beauty, he would nevertheless be criticized and accused of a false taste by someone else, who considered beauty in the object only as an adherent property (who looked to the end of the object), even though both judge correctly in their way: the one on the basis of what he has before his sense, the other on the basis of what he has in his thoughts. By means of this distinction one can settle many disputes about beauty between judges of taste, by showing them that the one is concerned with free beauty, the other with adherent beauty, the first making a pure, the second an applied judgment of taste" (Kant, 2000, pp. 115-116). 
of judgements of the persons that assume a different attitude towards the same object. Let us for instance analyse two persons, a botanist and an average nature lover, wording their observations on the beauty of a rose. The latter will beyond doubt be captivated by its form and, if his intention is not to pluck and sell it or if he is not overwhelmed and therefore blinded by its scent, contemplate it until he is bound by bliss. The botanist on the other hand, in spite of his knowledge of the world of plants or, in Kant's (2000) view because of it, will be fighting a losing battle. He will not be enchanted by the beauty of the rose as his cognitive powers will not be led into a free game, they will not be harmoniously matched, no reflex or mutual reflection between the aesthetic idea and the beautiful object will take place. He is in possession of knowledge that will allow him to quite accurately observe the imperfections of the calyx, length of the stalk or the colour of the petals. This means that imagination will be determined ${ }^{8}$ by the intellect which, supported by the idea of reason as regards the purpose of the object, is capable of defining what a perfect flower looks like.

This difference of judgements originates not only in different attitudes of the people who pass judgements on objects which are expressed by the contemplation

8 I do realise that the abovementioned problem formulated in this manner may be considered erroneous when beauty is discussed (adherent beauty though), which in Kant's concept is a notion that is subject to a reflexive power of judgement. However, although Kant does not explicitly claim so, if adherent beauty requires normal idea and the idea of reason that points to the purpose of the object, and to its perfection at the same time, the capturing of form in such an object is not fully realised by reflexive power of judgement. It is worth quoting a fragment of the third Critique which, however, does not fully explicate the nature of aesthetical judgements that relate to the objects of adherent beauty: „First, it should be noted that the beauty for which an idea is to be sought must not be a vague beauty, but must be a beauty fixed by a concept of objective purposiveness, consequently it must not belong to the object of an entirely pure judgment of taste, but rather to one of a partly intellectualized judgment of taste. I.e., in whatever kind of grounds for judging an ideal is supposed to occur, at its basis there must lie some idea of reason in accordance with determinate concepts, which determines a priori the end on which the internal possibility of the object rests. An ideal of beautiful flowers, of beautiful furnishings, of a beautiful view, cannot be conceived. However, an ideal of a beauty adhering to determinate ends, e.g., of a beautiful residence, a beautiful tree, beautiful gardens, etc., is also incapable of being represented, presumably because the ends are not adequately determined and fixed by their concept, and consequently the purposiveness is almost as free as in the case of vague beauty" (Kant, 2000, p. 117). Leaving aside the problematic issue of the ideal itself which, as we know from Kant's aesthetics only the human being can be, we will observe that the author of Critiques points to an important role of the determining notion, which is fulfilled by the idea of reason, in judging the 'ideal', and also to the fact that the object of adherent beauty is not fully subjected to pure judgements of taste. However, he does not make an ultimate explanation if these judgements are also judgements of the determining power of judging. This happens, in my opinion, because imagination becomes, at least partially, determined by the imagination of perfection and the purpose of the object. 
of the form, but also, if one may say this, in the nature of the judged object itself. The examples of free beauty presented by Kant (2000) include, apart from flowers, different birds and marine crustaceans which, as it may seem, are beautiful in their own right, not by reference to an idea or purpose. A similar situation exists with products of human hands, such as ornaments, mosaics or improvisations in music, communing with which does not curb or define our imagination, or determine it by the intellect. However, in this way we may never be able to savour the beauty of man, horse or building, or numerous other things for which the idea of perfection is self-apparent. The notion of purpose in these objects determines the manner of their capturing and taints the purity of aesthetic judgements which become judgements of perfection. Luckily, also in respect of them, Kant preserves the autonomy of taste in relation to external rules which might determine it, and proves its capability of passing judgements.

Such judgements are supported by the normal idea which allows to decide whether the object under scrutiny is near or far in reaching it in its representation. This is the essence of adherent beauty. Thus, being in possession of normal ideas of objects of each respective class, we may, by making comparisons of particular representations, decide of their value. Knowing the purpose for which something came to be, or the purpose that nature has, we know its perfection. It is constituted in the purposefulness of the entire species or class of objects. But what is this normal idea and how can it be reached?

The aesthetic normal idea is an averaged value „It is the image for the whole species - he says - hovering among all the particular and variously diverging intuitions of the individuals, which nature used as the archetype underlying her productions in the same species, but does not seem to have fully achieved in any individual” (Kant, 2000, p. 119). At the same time Kant makes a reservation that such image may constitute no prototype for beauty, but it represents its condition, delineates its correctness. Such an averaged image is out of necessity devoid of all the characteristic features for particular objects ${ }^{9}$. This means that in the formulation process of such idea in the imagination, out of many overlapping object representations of a particular class, they are eliminated. However, the fact remains that such averaged images are not only formed for various members of human body, such as the head, trunk, hands, or even mouth and eyes, but also for various natural,

9 In the remaining part of the text I will undertake to prove that it was Santayana's departure from what is averaged that will allow him to explicate the mechanism of constructing extraordinary literary characters, thanks to which the author of The Sense of Beauty goes further than Kant as regards explicating the mechanisms of imagination that serve this purpose. 
artistic, or everyday objects. The latter case, however will have to be understood in terms of perfection understood as adaptation of the object to its intended use.

The averaged value achieved by superimposing one thousand men on each other will, according to Kant (2000), be equal to one beautiful man. If we supplement it with the averaged images of different parts of man's body then the form will become a basis for the idea of beautiful man living in a concrete place in the world ${ }^{10}$. Multiple repetition of the capturing process will cause the emerging form to reflect the purpose for which it is supposed to be like this. However, for the purpose to reveal itself to us, the normal idea, which constitutes the evaluation criterion, requires support from the idea of reason. It is this idea that defines this purpose a priori, by which it delineates the internal capability of the object. Therefore, the judgements of taste that relate to adherent beauty are not pure judgements of taste, but they are partially based on the intellect, whereas the assessment of objects that fall under the category of such beauty depends on both the notion that defines what they should be, and their perfection.

It is worth adding at this point that the normal idea itself, as well as its most perfect expression in the form of a concrete representation, are something different from an ideal of beauty ${ }^{11}$ that can only be a man as a moral being, ideal thanks to due to his humanity ${ }^{12}$. This ideal would also constitute a specific archetype to taste,

10 See Kant (2000, pp. 118-119). It should be observed that Kant accurately recognises the role of conditions in which each one of us cumulates sensual experiences related to other people. By and large, in a particular place in the world, there live people who have been inhabiting that area for generations, belong to a certain race, display an array of characteristic features, etc. All this is conducive to our construction of norms of people who belong to a particular race, or even a particular country, especially if we have been brought up in it and live there. We are perfectly familiar with this as we can not only single out our compatriot in the crowd, but also an Asian, or even a Swede, a German or an Englishman. It is quite clear that normal ideas of people of different descent than ours should be fainter and poorer as they dwell on much less elaborate comparison material.

11 See an important comment by Kant: „Idea signifies, strictly speaking, a concept of reason, and ideal the representation of an individual being as adequate to an idea. Hence that archetype of taste, which indeed rests on reason's indeterminate idea of a maximum, but cannot be represented through concepts, but only in an individual presentation, would better be called the ideal of the beautiful, something that we strive to produce in ourselves even if we are not in possession of it. But it will be merely an ideal of the imagination, precisely because it does not rest on concepts but on presentation, and the faculty of presentation is the imagination.” (Kant, 2000, p. 117).

12 See the following excerpt: „Only that which has the end of its existence in itself, the human being, who determines his ends himself through reason, or, where he must derive them from external perception can nevertheless compare them to essential and universal ends and in that case also aesthetically judge their agreement with them: this human being alone is capable of an ideal of beauty, just as the humanity in his person, as intelligence, is alone among all the objects in the world capable of the ideal of perfection” (Kant, 2000, p. 117). 
an unparalleled model based on a certain ,indeterminate idea of a maximum, but [as such - K.W.] cannot be represented through concepts, but only in an individual presentation" (Kant, 2000, p. 117), in a certain ideal of the imagination. There can be only one such an ideal of beauty that, according to Kant, may enjoy general appreciation. A different approach is applied in relation to the normal ideal, as depending on the empirical material around us, the averaged images that emerge vary. In this sense, my normal idea of the face of an Asian person will differ from the same idea formed by an inhabitant of China. Thus, our normal ideas of beautiful men and women will be different, as Kant already argued in his early essay entitled Observations on the Feeling of the Beautiful and Sublime ${ }^{13}$ where, among other things, he analyses characters of nations and their inclinations.

\section{SANTAYANA'S REFLECTIONS ON AESTHETIC TYPES AND THE FORMATION OF LITERARY CHARACTERS}

In The Sense of Beauty, George Santayana (1896) proposes a slightly different from Kantian use of averaged images of the imagination. In his opinion they serve organisation of any material of human sensual experience and explanation of some of the aspects of a creative process. Let us take a closer look at their roles.

According to the Spanish philosopher our way of perceiving a form does not depend on whether an external stimulus through which it is given to us is pleasant, but to a large extent on whether the sole reaction to it is pleasant, which gains importance when the general implication of the perceived objects depends to a greater degree on our past experiences and inclinations of our imagination rather than its structure. Apart from that, an undeniable impact on the said reaction is exerted by subjective factors, such as physical condition, education or talent. And the more the unspecified the object, the more frequently the attempts towards its particularisation are vocalised ${ }^{14}$.

13 See Kant (2011). In this early work the philosopher from Konigsberg highlights the partial relativity of the ideas concerning perfection, both physical and spiritual properties of men and women, while at the same time points to their source in the distinctness of empirical and educational conditions existent in various countries. The majority of the provided examples of beauty belong to adherent beauty. However, treating this pre-critique essay, constituting mainly a generalisation of a common experience, as a complement or an introduction to The Critique of Judgement written 26 years later is a mistake and a major simplification. Both works are written from a different perspective and despite the coincidental names of certain discussed issues, they are approached in a dissimilar way.

14 See Santayana (1896, p. 113). 
In such a particularisation we compare the perceived form with a certain familiar shape, and once it is successful, we deal with the recognition, which gives us a certain amount of pleasure ${ }^{15}$. This happens because the said recognition constitutes nothing else but the discovery of an aesthetic type, a certain pattern of perception to which the currently observed form fits. A similar situation will concern the objects that we know and whose form is specific enough for us to involuntarily recognise them as examples of particular classes of objects.

According to Santayana, the aesthetic value of a form is on the one hand determined by the value of an aesthetic type, while on the other, and it is the more important element of the two, „the relation of the particular impression to the form under which it is apperceived, (...) [because it - K.W.] determines the value of the object as an example of its class” (Santayana, 1896, p. 115). This means that the most important aspect in form perception is that thanks to such acts our minds create patterns through the prism of which we will then evaluate particular examples. Such patterns, or as Santayana refers to them on different occasions ideas of class or aesthetic types, emerge as a result of multiple encounters with ideas of individual objects and constitute their remnants ${ }^{16}$. The internal similarity of particular impressions, and, at times, the identity of their relations causes that without being aware of this fact we collect them into a uniform and blurry memory that replaces all of them. This is what we do with our entire experience, as since it is to be available to us it must be classified, whereas certain generalised impressions, definitive images must become class representatives ${ }^{17}$.

What is curious, the author of the Sense of Beauty allows for the possibility that a given averaged image will contain very few sensual qualities, since it appears that what can constitute a certain class of objects can be, for instance, a sound of an utterance, which is the only common element present in all cases falling under a given class. However, since every human meets with different ideas of individual

15 This type of an experience is nothing else but searching, for instance, for particular shapes of animals, faces or objects in the clouds.

16 It means that we create such aesthetic types or class ideas for all the objects that are available to us in a sensual manner. However, as we will see Santayana does not stop here and claims that these types or ideas may be nearly completely deprived of sensual elements.

17 See Santayana (1896, pp. 117-121). It needs to be added here that Santayana pertinently observes that „when various objects have many common characteristics, the mind is incapable of keeping them apart. It cannot hold clearly so great a multitude of distinctions and relations as would be involved in naming and conceiving separately each grain of sand, or drop of water, each fly or horse or man that we have ever seen. The mass of our experience has therefore to be classified, if it is to be available at all. Instead of a distinct image to represent each of our original impressions, we have a general resultant a composite photograph of those impressions” (Santayana, 1896, p. 118). 
objects, our generic ideas or perception models will differ substantially, and by being the result of a subjective attitude, they indicate that each such generalisation does not entirely correspond to an averaged quality, as mentioned by Kant. In Santayana's concept (1896) individual ideas depend not only on the attention given to their objects but also on their own nature, as they themselves become effaced and blended into a single image, thus losing their individual character. Such an idea, however, designates the extremes beyond which we will never find beauty. More importantly, it marks out the course the departure from which towards the pleasure of an observer, will lead him to an aesthetic ideal, which in a majority of cases is significantly different from mediocrity ${ }^{18}$.

As regards human character, on the other hand, Santayana (1896) expresses an opinion that in this case it would be more proper to state that it constitutes ,,an intellectual symbol and short-cut to a particular type of actions rather than a recognition that such actions are a manifestation of character. This is due to the fact that actions constitute a piece of information and a character a concluded principle which as such, despite its name, is never more than an a posteriori description and a sum of what is subsumed under this notion” (Santayana, 2014, p. 182). That is why he agrees with Aristotle who, while characterising a tragedy, speaks of an imitative representation that is not focused on people but their activities and lives ${ }^{19}$. Hence the idea to portray human characters with the use of the most characteristics acts.

The character sketched by an artist constitutes a certain type of unity falling within a particular type, although the protagonist is not a sensual representation, as Santayana notes, but rather ,,a rationalistic synthesis of successive acts and feelings, not combinable into any image" (Santayana, 1896, p. 177). This, as it seems, causes that an ideal character to a great extent depends on subjective elements, such as, for instance, a spontaneous expression of the feelings and will of the author. On the other hand, however, it is still possible to point to a certain similarity of such a character creation ,to the process by which the imagination produces the type of any physical species" (Santayana, 1896, p. 177), as it is sufficient to adopt any feature of character, make it the core characteristic of our protagonist and around it accumulate some isolated observations. Of course this can be done following Santayana's suggestions, i.e. by wandering around with a notebook, as it was the case, for instance, with Balzac.

18 This issue is discussed in the third part of my article.

19 See the following excerpt: „Tragedy, then, is an imitation of an action that is serious, complete, and of a certain magnitude; in language embellished with each kind of artistic ornament, the several kinds being found in separate parts of the play; in the form of action, not of narrative; through pity and fear effecting the proper purgation of these emotions” (Aristotle, 1922, p. 23). 
Let us look at his example. It is true that there are numerous anecdotes regarding this great artist, describing him as a man completely overwhelmed by the world created and presented in his novels, which he believed to be more real than the one where, for instance, he was expected to meet with his publisher. What is still astounding, however, is his perfection in portraying all types of human characters and the amazing precision, detailedness and accuracy in presenting the complex world of „human comedy”, as he called it.

„It should be assumed - as Tadeusz Żeleński-Boy puts it - that he [Balzac author's note] not only had a gift of observation but even of a vision that enabled him to reproduce with infallible accuracy and plasticity the entire human being, social group, state of mind on the basis of a single trait or several words. After all, we remember that especially in the first period of his life he had plenty opportunities to become well familiarised with this area. The three years of a training period in a lawyer's office let him find out a lot about Parisians. This was followed by years of unsuccessful enterprises, financial struggles; his first steps into the literary world, worldwide successes and failures. He knew Paris inside out, knew everything it had to offer. He was an expert in „intervention”, knew exactly how to approach people in order to extract what he needed. (...) In Madame de Berny he found a repository of memories of former monarchy; Duchess d`Abrantès, the author of the famed memoirs served him as a living Napoleonic tradition; Duchess des Castries introduced him to the world of aristocratic subtleties (...). During his long stays in the province he collects information, becomes extensively familiar with local geography and history, enters the life of each town” (Żeleński-Boy, 1957, pp. 18-19).

Each of us has a similar way of coping with the world, however not everyone becomes a great artist. Balzac was certainly distinguished by his imagination, thanks to which he easily combined whatever was offered to him by his senses into new worlds. He was a brilliant observer, it was his imagination that he owed the ability to so masterly depict the slightest nuances of human nature, which on the other hand was possible thanks to gathering observations concerning all kinds of people and equipping them with proper headings. This is the way to obtain the possibility of a later selection of materials from observations which are needed in order to be able to plot them aptly into the described series of events. This is what writers do; of course they do it intentionally while every other person does it involuntarily and almost continuously. Here again the previously mentioned necessity to classify various elements of our experience becomes visible. This is how we collect images and data concerning all kinds of possible human behaviours. We establish classes of people, characters, passions, professions, nations and customs. 
Nonetheless, Santayana rightly notes that they all „give the average, or at most the salient, points of the type, but the great characters of poetry (...) are no averages, they are not even a collection of salient traits common to certain classes of men. They seem to be persons; that is, their actions and words seem to spring from the inward nature of an individual soul” (Santayana, 1896, p. 179). Thereby, ideal characters will require exceeding of the averaged image, a simple accumulation of typical traits or behaviours, the enlivening naturalness, idealisation avoiding elimination of individualism, synthesis and inspiration.

\section{FROM AN AVERAGED IMAGE TO A JOYFUL EXPRESSION. FROM MEDIOCRITY TO AN IDEAL}

An aesthetic ideal that constitutes one of the general types must, analogically to them, possess at least one similar underlying mechanism of formation. This means that it is also based on the collected material of perception, which in this case, however, is to a larger degree characterised by an individual aesthetic overtone than the generated averaged image. It does not solely result from an accuracy of the conducted observations as the significant role in creating any general types is played by our interest in the object. More specifically, the traits that we find attractive and because of it distinguished. It is them that cause communing with objects that possess these attributes to form individual implications, specifically related to a particular person. Exactly the same pattern will be applicable in the case of aesthetic ideals which reflect our aesthetic interests. This way, taking as a base the averaged images of objects, such ideals will move away towards what brings us pleasure ${ }^{20}$. And pleasure, according to Santayana (1896) will be more easily induced by what is magnified and at the same time more distinguishing and noticeable. This is how the individually tinted pleasures help us create ideals, thus revealing their meaning that the author of the Sense of Beauty sought in the representation of something and giving specific satisfaction ${ }^{21}$.

However, complete definition of the departure from an averaged image of things is not exhausted in sole indication of the role of pleasure in the entire process. Indeed, it is also necessary to explain how it is translated into the depiction of ideal characters, as well as how it happens that they become models with which we

20 See Santayana (1896, pp. 121-122).

21 See Santayana (1896, pp. 124-125). 
compare the real people ${ }^{22}$. At this point of Santayana's reflections it is necessary to note that he is once more inspired by concept of the Stagirite, who claimed „that it is not the function of the poet to relate what has happened, but what may happen" (Aristotle, 1922, p. 35), which remains in concord with the opinion of the Spanish thinker that fiction becomes a criterion of naturalness. According to the latter, similarly to the beliefs of the author of Poetics, poetry is truer than history ${ }^{23}$. This genuineness is mainly manifested in the naturalness of the created character, the vividness of behaviour, in our conviction that we are faced not with an artist's creation but a person of flesh and blood, who cannot be an averaged image of people in general nor a product of an isolated profession or feature of character. This would have caused artificiality to be felt even more intensively.

Other people's characters always constitute a certain type of mystery for us, as we know nothing about their motifs of conduct, and basing on the sensual manifestations of their actions we are only able to formulate more or less accurate ideas of those individuals. A keen observer of social life, a codifier of various human behaviours, customs, ridiculousness, weaknesses or other manifestations of human nature has, due to the rich comparative material, much greater chances to detect falsity, artificiality or unnaturalness in one's behaviour than a person that merely touches the surface of the sensual epidermis of the quotidian spectacle. He/she can debate on psychological types, characters, professions and passions, precisely describe each class once the artist presents in his work an ideal protagonist, effortlessly recognise the ideal embodiment of his/her own notions ${ }^{24}$.

22 What is interesting, this latter issue reveals a certain likeness to the Kantian way of understanding works of genius, which, although only by way of example, still outline the principles for art and become models for successive generations of artists. They are clearly not models to be imitated but rather to enable creative undertaking of the aesthetic idea realised within them. Still, they can constitute models with which we can juxtapose the diversified perception material. Then, however, it will not have much in common with the free beauty that is largely discussed in the Analytic of the Beautiful.

23 See the following excerpt: „Poetry, therefore, is a more philosophical and a higher thing than history: for poetry tends to express the universal, history the particular” (Aristotle, 1922, p. 35). It is worth adding, however, that the genuineness or naturalness of an ideal protagonist is found by Santayana in particular expressions of its behaviour, in the forcible expression of a typical feature of character or an attribute of the mind. Here, fiction still remains truer than many sensual perceptions depicted by us in a biased manner, constituting the basis for representing someone's character, reflecting it in ourselves.

24 The fact that the man is a graceful material, with all the manifestations of his existence, both in the study of his nature and for the immortalisation in the works of art is confirmed by the following fragment: „,The human figure, elementary passions, common types and crises of fate- these are facts which pass too constantly through apperception not to have a normal aesthetic value. The 
This conformity between the realisation of an artist's intent and his knowledge of the human nature enables him to make a complete judgement on the naturalness of the presented character, on the criterion represented by it, both for the said naturalness and the beauty itself. How very far such a creation falls from a simple generalisation, from an idealisation that eliminates all details ${ }^{25}$ that are so well known from the behaviours of people that surround us. There is absolutely nothing indirect in it. As Santayana puts it:

Imagination generates as well as abstracts; it observes, combines, and cancels; but it also dreams. Spontaneous syntheses arise in it which are not mathematical averages of the images it receives from sense; they are effects of diffused excitements left in the brain by sensations. These excitements vary constantly in their various renewals, and occasionally take such a form that the soul is surprised by the inward vision of an unexampled beauty (Santayana, 1896, pp. 181-182).

If an artist is lucky enough that his power of expression is capable of producing such syntheses, all that is left for him to do is realise his intentions regarding a given matter, give them a final shape and realise the ideal that will always bear an individual imprint of a dual nature, if we may say so. On the one hand an artist will mark it with his genius and the principles that prevail in him, whereas on the other, the ideal will embody a certain „,brute fact”, as Santayana suggests. As in order to fully portray someone's character in such a manner as to seem live to us, more perfect than in a real person, it cannot be devoid of an expression. It cannot just present general features, quite to the contrary, only through concreteness, individuality and a characteristic trait is it possible to present to the imagination an ideal of a particular personality. Kant (2000, p. 191) states that certain art products are said to be deprived of a spirit. Here we might say exactly the same thing. An ideal character or an embodied ideal should reflect human spirit, its invigorating principle, supported of course by its dominant traits which are distinctive, visible and serve as a core or base to the formation of its image. They constitute its individuality that may easily tone in with our entire comparative material and

artist who can catch that effect in its fullness and simplicity accordingly does immortal work" (Santayana, 1905, p. 203).

25 Despite what we read in the Reason in Art, namely „Yet the ideal of mastery and idealisation remains the same, if any one could only attain it: mastery, to see things as they are and dare to describe them ingenuously; idealisation, to select from this reality what is pertinent to ultimate interests and can speak eloquently to the soul" (Santayana, 1905, pp. 114-115), it is necessary to emphasise that idealisation always constitutes a certain type of simplification, representation deprived of anything that is characteristic. And in such a depiction it cannot largely contribute to the construction of an ideal. 
knowledge of the man. Imagination will then quickly recognise the synthesis behind such a character and recall many of those images that are matched with it, and the representations of which it constitutes and embodies in an ideal manner ${ }^{26}$.

\section{INSTEAD OF A CONCLUSION}

The presented juxtaposition of the views of the two thinkers was aimed to show that both of them indicate similar mechanisms of functioning of the imagination. The absence of references to the issue of genius in Kant's depiction may lead to the conclusion that the proposed comparison is incomplete. Nonetheless, it is my conviction that the plane used in the above analysis did not allow for the introduction of his artist-genius concept. Firstly, this was due to the fact that based on the normal idea we do not create free but adherent beauty, for which purpose genius is no longer indispensable. Kant seeks its task elsewhere, which also should not come to us as a surprise, although it is necessary to admit that in the acts of genius we find the mechanism of perception „condensation” and synthesis, as Santayana put it. Nonetheless, its works certainly do not constitute the averaged images established in the course of daily experiences. It seems, however, that the philosopher from Konigsberg, would have agreed with Santayana's opinion, according to which:

The poet has only to study himself, and the art of expressing his own ideals, to find that he has expressed those of other people. He has but to enact in himself the part of each of his person ages, and if he possesses that pliability and that definiteness of imagination which together make genius he may express for his fellows those inward tendencies which in them have remained painfully dumb. He will be hailed as master of the human soul (Santayana, 1896, p. 185).

This fact should not be surprising, as since genius mainly is based on the imagination and both thinkers saw similar principles of its actions, then in its certain manifestations it must function in the same manner following the concepts of both of them.

26 See the following excerpt: „An artist is a dreamer consenting to dream of the actual world; he is a highly suggestible mind hypnotised by reality. Even barbaric genius may find points of application in the world. These points will be more numerous the more open the eyes have been, the more docile and intelligent the mind is that gathers and renders back its impressions in a synthetic and ideal form. Intuition will then represent, at least symbolically, an actual situation. Grimace and gesture and ceremony will be modified by a sense of their effect; they will become artful and will transform their automatic expressiveness into ideal expression” (Santayana, 1905, p. 39). 
Secondly, Santayana's reflections around generic ideas, aesthetic types or even ideals, contrary to Kant's views, have a practical dimension, going far beyond the narrowly understood aesthetic experience. The author of the Sense of Beauty provides us with an explanation of the functions of a tool with the use of which each our sensual experience is particularised with the classification of objects as particular types. These can be characters of persons, their professions, and also faces, ways of smiling, dressing or walking. This is complemented with an organisation of the entire perception material which contains all the objects of everyday use, nature and art. Thanks to that Santayana's concept is to a greater extent conducive to human orientation in the world, understanding it and communicating judgements on it to others as compared with that presented by Kant.

\section{References:}

Aristotle (1992). Poetics. in: The Poetics of Aristotle (p. 6-111). Edited with critical notes and a translation by S.H. Butcher. London: Macmillan and Co. Limited.

Dickie, G. (1996). The Century of Taste. The Philosophical Odyssey of Taste in the Eighteenth Century. Oxford, New York: Oxford University Press.

Grzeliński, A.; Wawrzonkowski, K. (2014). Wstęp tłumaczy. In: G. Santayana, Poczucie piękna. Zarys teorii estetycznej. Toruń: Wydawnictwo Naukowe UMK.

Guyer, P. (1997). Kant and the Claims of Taste. Cambridge University Press.

Guyer, P. (2005). Values of Beauty: Historical Essays in Aesthetics. Cambridge University Press.

Guyer, P. (2008). Knowledge, Reason, and Taste: Kant’s Response to Hume. Princeton University Press.

Kant, I. (2011). Observations on the Feeling of the Beautiful and Sublime. In: I. Kant, Observations on the Feeling of the Beautiful and Sublime and Other Writings (pp. 11-64). Edited by P. Frierson and P. Guyer. Cambridge University Press.

Kant, I. (2000). Critique of the Power of Judgment. Edited and translated by P. Guyer. Cambridge University Press.

McCormick, J. (1988). George Santayana. A biography. New York: Paragon House.

Santayana, G. (1986). Persons and Places: Fragments of Autobiography, ed. W.G. Holzberg, H.J. Saatkamp Jr., Cambridge (Massachusetts)-London.

Santayana, G. (1896). The Sense of Beauty. Being the Outlines of Aesthetic Theory. New York-Chicago-Boston: Charles Scribner's Sons.

Santayana, G. (1905). The Life of Reason; or the Phases of Human Progress, vol. 4: Reason in Art. New York: Charles Scribner's Sons.

Wenzel, C. (2005). An Introduction to Kant's Aesthetics: Core Concepts and Problems. Wiley-Blackwell.

Żeleński-Boy, T. (1957). Wstęp. In: H. Balzac, Komedia Ludzka, Studia obyczajowe. Sceny z życia prywatnego (v. 1, pp. 5-31), trans. T. Żeleński-Boy. Warsaw: Czytelnik. 